\title{
Productive and reproductive characteristics of hens in the parent flock when including sprouted barley in the diet
}

\author{
Rinat Gadiev ${ }^{1,2}$, Danis Khaziev $^{2}$, Niyaz Subhankulov ${ }^{1}$, Venera Abdrakhmanova ${ }^{1}$, and \\ Tatyana Sedykh ${ }^{1,3, *}$ \\ ${ }^{1}$ Ufa Federal Research Center of the Russian Academy of Sciences, Bashkir Research Institute of \\ Agriculture, Ufa, Russia \\ ${ }^{2}$ Federal State Budgetary Educational Institution of Higher Education Bashkir State Agrarian \\ University, Ufa, Russia \\ ${ }^{3}$ Federal State Budgetary Educational Institution of Higher Education Bashkir State Pedagogical \\ University named after M. Akmulla, Ufa, Russia
}

\begin{abstract}
This research aimed to study the productive and reproductive qualities of parent herd hens having the diet with sprouted barley in whole grain and crushed form. The objectives included studying the flock liveability and analysing productive and reproductive characteristics of laying hens in the Ross 308 parent flock. The first control group received a diet with unsprouted whole barley, the second control group with unsprouted crushed barley, the first experimental group with sprouted whole barley, the second experimental group with sprouted crushed barley. The scientific and economic experience lasted until the bird reached the age of 60 weeks. The research findings showed that sprouted crushed barley in the diet of the parent flock hens contributes to better poultry growth and development, increases the weight of incubation eggs by an average of $0.3 \%$, the yield of incubation eggs by $0.5 \%$, hatchability by $0.3 \%$, hatchability of young birds by $0.2 \%$, enlarges the poultry liveability, egg production indicators per an initial and an average laying hen, reduces the feed conversion rate.
\end{abstract}

\section{Introduction}

Currently, the poultry industry is one of the most dynamically developing Russian meat production industry branches. This is facilitated by intensified production, specialization and concentration, a high level of mechanization and automation, highly productive poultry crosses, and modern technologies for keeping and feeding. Rationed, balanced and fullfledged feeding of meat poultry is the key to high productivity and good economic indicators of production $[1,11]$. A growing body of literature recognises the importance of fodder and feed additives that provide poultry with necessary nutrients and biologically active substances to fulfil their genetic potential.

\footnotetext{
${ }^{*}$ Corresponding author: sci_secr_bniish@bk.ru
} 
Sprouted grain in the diets of farm animals has been well studied. Some findings indicate that the grain nutritional value and taste qualities go up when sprouted, ensuring better feed intake by animals [1,2,5]. The most sprouted are wheat, barley and oats. Thus, sprouted barley can be characterized by the lower starch content by $60 \%$ and the higher sugar rate by $20-25 \%$ compared to the initial level. 24 hours after the sprouting starts, many enzymes in barley and microorganisms in the grain mass are activated, including alphaamylase, beta-amylase, phosphorylase, ribonucleases, peroxidases, catalase, etc. In 72 hours, reducing sugars in the grain increases by 2 times due to the starch hydrolysis while its content gradually decreases. Sprouting produces vitamin $\mathrm{C}$ and increases vitamins $\mathrm{E}$ by 3 times, B-group by 6-8 times [8].

Numerous studies have demonstrated that sprouted grain has a beneficial effect on the livability of young animals, productive and reproductive indicators of adult livestock. Thus, feeding sows with 5,10 and $15 \%$ of sprouted barley 30 days before farrowing reduced the number of stillbirths and enlarged the number of live piglets by an average of 0.6, 0.9 and 1.0 piglets compared with the control group. The live weight of piglets aged 2 and 7 months was higher by $4.1-12.9 \%(\mathrm{P}<0.05-0,01)$, their livability increased by $5,6-10,4 \%$ compared to the control group [6]. It has been demonstrated that feeding sprouted barley to piglets from four to seven months significantly increases the volume of meat and reduces its cost. Daily consumption of $10 \%$ of the daily grain ration provides the best indicators of animal productivity and economic efficiency [7]. Sprouted barley soaked in water in the calves ' diets increased productivity by $2 \%$, reduced feed costs by $1.8 \%$, and the weight gain costs by $1.94 \%[8]$.

Previous research conducted by the authors of the given paper has shown the influence of sprouted barley on the productivity of meat-producing hens. The study established the feeding rate and mode $(20 \mathrm{~g}$ per $1 \mathrm{head} /$ day in the evening). Sprouted barley enhanced fertilization by $1.5 \%$, hatchability by $2.3 \%$, the number of chicks hatched by $2.3 \%$ and decreased incubation waste by $3.2 \%$, including eggs with a blood ring by $0.5 \%$, frozen embryos by $0.8 \%$, weak and crippled chicks by $0.4 \% \ldots$ [3]. However, it should be noted that hens did not always eat whole-grain sprouted barley well.

The present study aimed to analyze the productive and reproductive qualities of parent herd hens having the diet with sprouted barley in whole grain and crushed form. The objectives included studying the flock liveability and analysing productive and reproductive characteristics of laying hens in the Ross 308 parent flock.

\section{Materials and methods}

The research was carried out on laying Ross-308 hens in the conditions of the Tuimazinsky poultry farm. To conduct the study, two control and two experimental groups were created. The experimental groups consisted of 140-day-old 110 birds chosen by live weight and development based on the analogue method. The first control group received a diet with unsprouted whole barley, the second control group with unsprouted crushed barley, the first experimental group with sprouted whole barley, the second experimental group with sprouted crushed barley. The scientific and economic experience lasted until the bird reached the age of 60 weeks. The experimental birds were kept under the same conditions according to the methodological recommendations for growing the Ross-308 hens and the "Methodological recommendations for the technological design of poultry enterprises RDAPK 1.10.05.04-13 "(approved and put into effect by the Russian Ministry of Agriculture on 30.09 .2013$)$.

The barley sprouting was as follows: preliminary disinfection of the grain with a lowdose $0.01 \%$ solution of potassium permanganate (15-20 minutes), soaking the grain in 20$25^{\circ} \mathrm{C}$ water ( 8 hours), placing $4.0 \mathrm{~kg}$ of grain per $1 \mathrm{~m}^{2}$ in a tray (air temperature $20-26^{\circ} \mathrm{C}$ ), 
daily moistening with water with a spray gun until white sprouts are $0.5-2.0 \mathrm{~cm}$ long. Then part of the sprouted grain was subjected to grinding, some remained in the whole form.

During the experiment, the following indicators of the experimental hens were considered: live weight (individual weighing was carried out at the age of 20,30, 40, 50 and 60 weeks), the flock livability during the period of the experiment, egg-laying capacity for the initial laying hen (the ratio of the total egg production to the initial flock), egglaying capacity for the average laying hen (the ratio of the total egg production to the average flock), assessing the quality of incubation eggs (at 31 weeks, at the peak of egg production, by evaluating three batches of eggs received from each experimental group) according to the indicators: weight of incubation eggs, by weighing (at the age of 28, 40 and 60 weeks), selecting eggs for incubation, excluding eggs with a fight and a notch, small, two-yolked, irregular-shaped, marble-shelled, with growths on the shell, with blood and other inclusions, according to the results of the assessment, the yield of incubation eggs was determined (the percentage of incubation eggs received from the parent herd suitable for incubation), fertilization (the proportion of fertilized eggs in the total batch of eggs laid in the incubator), hatchability (percentage of hatched young birds from the number of fertilized eggs), hatchling (percentage of hatched young birds from the number of eggs laid for incubation), as well as evaluation of the results of incubation according to the methods developed at the All-Russian Poultry Research and Technology Institute (Sergiyev Posad). Statistical processing of the research results was performed by standard methods using the software application Microsoft Excel.

\section{Results and discussion}

Live weight is an important indicator of the growth and development of biological organisms. It demonstrates a physiological state of an animal as well. The live weight dynamics of Ross-308 laying hens is shown in Figure 1.

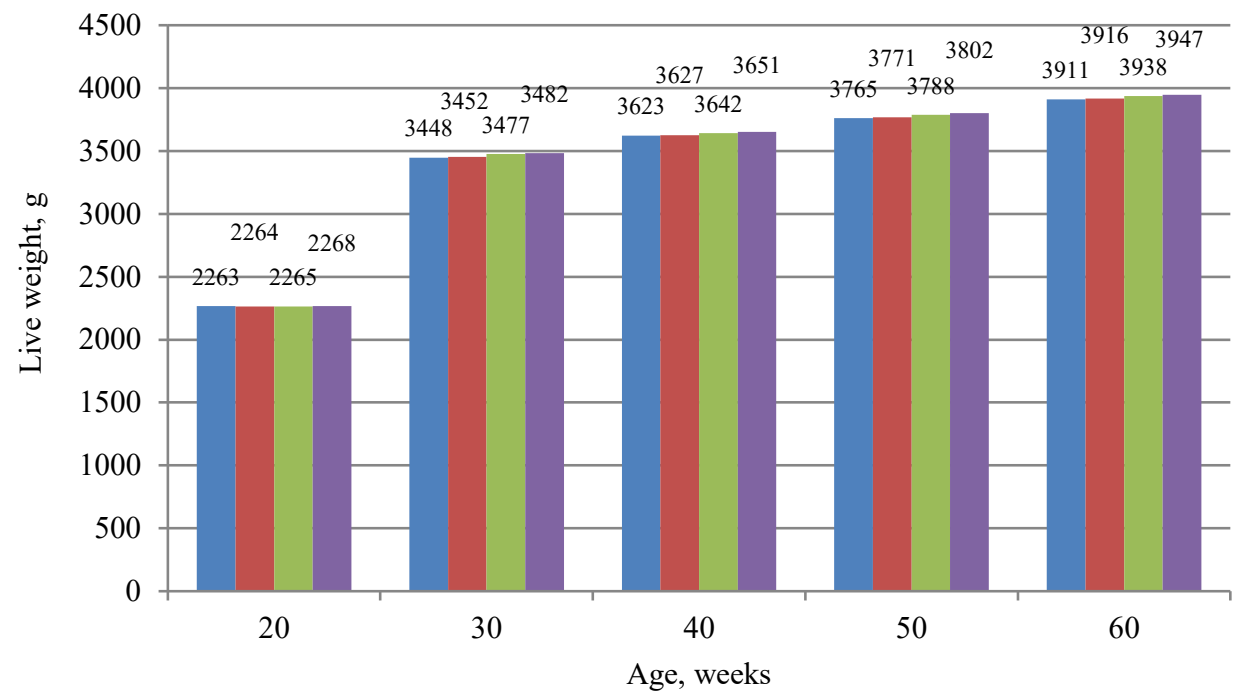

घControl group $1 \quad$ Control group $2 \backsim$ Experimental group $1 \quad$ Experimental group 2

Fig. 1. The live weight dynamics of experimental laying hens. 
The findings indicate that laying hens increase their live weight with age, but intergroup differences are insignificant. Live weight of poultry in the experimental groups consuming sprouted barley tended to grow. Thus, the 1 st experimental group (feeding with wholegrain sprouted barley) exceeded the live weight in the 1 st control group by $0.83 \%$ at 30 weeks, by $0.52 \%$ at 40 weeks, by $0.71 \%$ at 50 , by $0.69 \%$ at 60 weeks. A similar trend was observed in poultry of the 2 nd experimental group (feeding with crushed sprouted barley). The live weight index exceeded the control at the specified age, respectively, by $0,86 \%$, $0,66 \%, 0,82 \%, 0,78 \%$. The intergroup difference in live weight indicators in feeding wholegrain, crushed sprouted, or unsprouted barley was insignificant and amounted to 0.12 $0.27 \%$ (the first experimental group had higher indicators). When feeding sprouted barley, the difference was greater and equated to $0.86 \%$ at 30 weeks; $0.66 \%$ at 40 weeks; $0.81 \%$ at 50 weeks and $0.78 \%$ at 60 weeks (the second experimental group poultry fed crushed sprouted barley had higher indicators). The obtained data indicate that Ross 308 cross laying hens consuming crushed sprouted barley increase the live weight better.

Incubation eggs of parent flock laying hens in the experimental groups were evaluated at the peak of egg production, falling on the 31 and 32 weeks of egg-laying. The egg weight of meat hens is one of the main properties that characterize the reproductive ability of the parent flock.

Table 1. Weight of incubation eggs in the experimental groups

\begin{tabular}{|c|c|c|c|c|}
\hline \multirow{2}{*}{ Age, weeks } & \multicolumn{4}{|c|}{ Group } \\
\cline { 2 - 5 } & 1st control & 2nd control & 1st experimental & $\begin{array}{c}\text { 2nd } \\
\text { experimental }\end{array}$ \\
\hline 28 & $54.2 \pm 0.50$ & $54.5 \pm 0.23$ & $56.1 \pm 0.50$ & $56.2 \pm 0.45$ \\
\hline 40 & $65.3 \pm 0.41$ & $65.4 \pm 0.41$ & $67.2 \pm 0.28$ & $67.4 \pm 0.51$ \\
\hline 60 & $70.1 \pm 0.54$ & $70.3 \pm 0.71$ & $72.2 \pm 0.43$ & $72.5 \pm 0.52$ \\
\hline
\end{tabular}

It should be noted that the results of weighing hatching eggs demonstrated a slight difference between the indicators, intergroup differences were insignificant. With age, the egg weight increase, which is a physiological pattern. On average, the egg weight increased by $15 \%$ from 28 to 40 weeks and by $20 \%$ to 60 weeks. The obtained results of weight for incubation eggs corresponded to the poultry age and cross. The weight of incubation eggs in poultry of the experimental groups fed sprouted barley tended to rise. Thus, the first experimental group of birds exceeded the first control group by $3.4 \%$ at 28 weeks, $2.83 \%$ at 40 weeks, and $3.0 \%$ at 60 weeks; similar results were observed when comparing the second experimental and second control groups. The egg weight was higher by $3.02 \%, 3.0 \%$, $3.03 \%$, respectively. The weight of eggs in the second experimental group fed crushed sprouted barley exceeded the same indicator in the first experimental group by $0.20 \%$, $0.3 \%, 0.41 \%$ at the age of 28,40 and 60 weeks, respectively. Thus, when feeding crushed sprouted barley, incubation eggs of laying hens have a higher weight.

The reproductive qualities of poultry in the experimental groups are presented in Figure 2. 


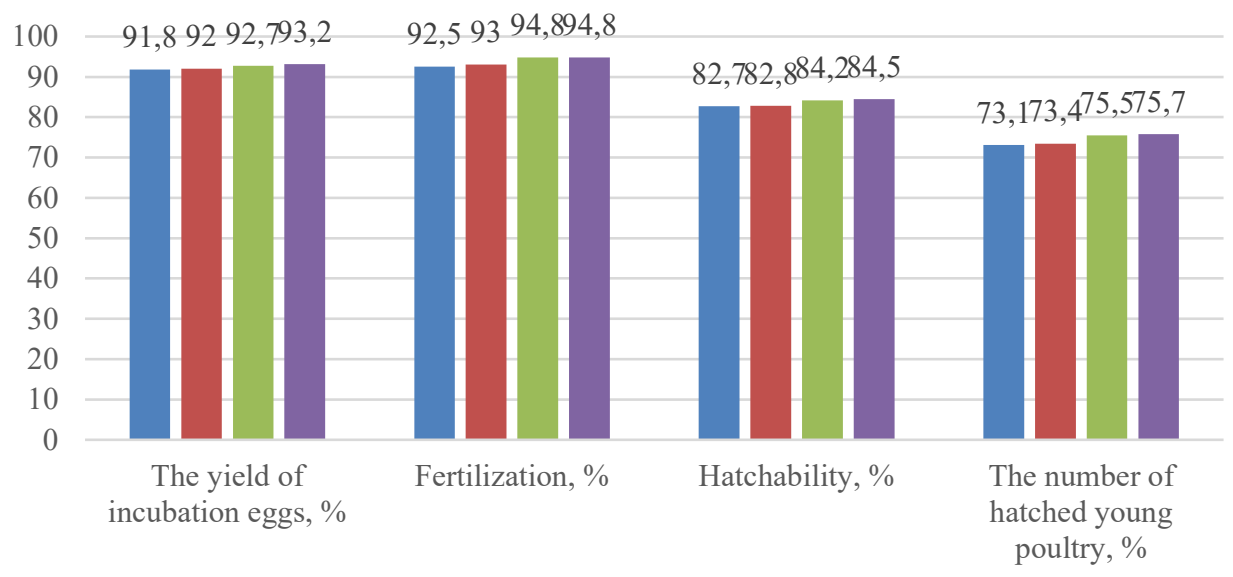

घControl group 1 a Control group 2 Experimental group 1 Experimental group 1

Fig. 2. The reproductive qualities of poultry in the experimental groups.

The findings illustrate an increase in the indicators of the reproductive ability of poultry in the experimental groups, where the diet included sprouted barley. The yield of incubation eggs in the first experimental group is higher than in the first control group by $0.9 \%$, egg fertilization by $2.3 \%$, hatchability by $1.5 \%$, the number of hatched young birds by 2.4 . In the second experimental group, these indicators were higher by $1,2 \%, 1,8,7 \%$, $2,4 \%$, respectively. Compared with the second control group, indicators in the second experimental group, given crushed sprouted barley, were higher by $0.5 \%, 0.4 \%, 0.3 \%$ and $0.3 \%$, respectively. Thus, feeding crushed sprouted barley increases the yield of incubation eggs, fertilization, hatchability and the number of hatched young birds.

The findings are consistent with the results of previous studies conducted by Charyev et al. (2015). They observed that whole-grain sprouted barley in the diets of the parent flock meat hens had increased fertilization by $1.5 \%$, hatchability by $2.3 \%$, the number of hatched young poultry by $2.3 \%$, while the incubation waste had dropped by $3.2 \%$, including eggs with blood ring by $0.5 \%$, frozen embryos by $0.8 \%$, weak and invalid ones by $0.4 \%$ [4]. Experiments of Tatianicheva et al. (2021) with sprouted grain added to full-fledged mixed fodder in the evening established that experimental groups exceeded the control poultry. Thus, the third experimental group had higher hatchability by $2.3 \%$, the second group by $0.5 \%$, the fourth by $1.6 \%$, respectively. An excellent result was obtained by the indicator of the number of hatched birds, characterized by the percentage of viable young birds from the number of incubated eggs. While this indicator was $72.4 \%$ in the control group, it was higher in the experimental groups by $1.6 \% ; 3.2 \%$ and $2.7 \%$, respectively [10].

Figure 3 shows the productivity of laying hens in the experimental groups. 


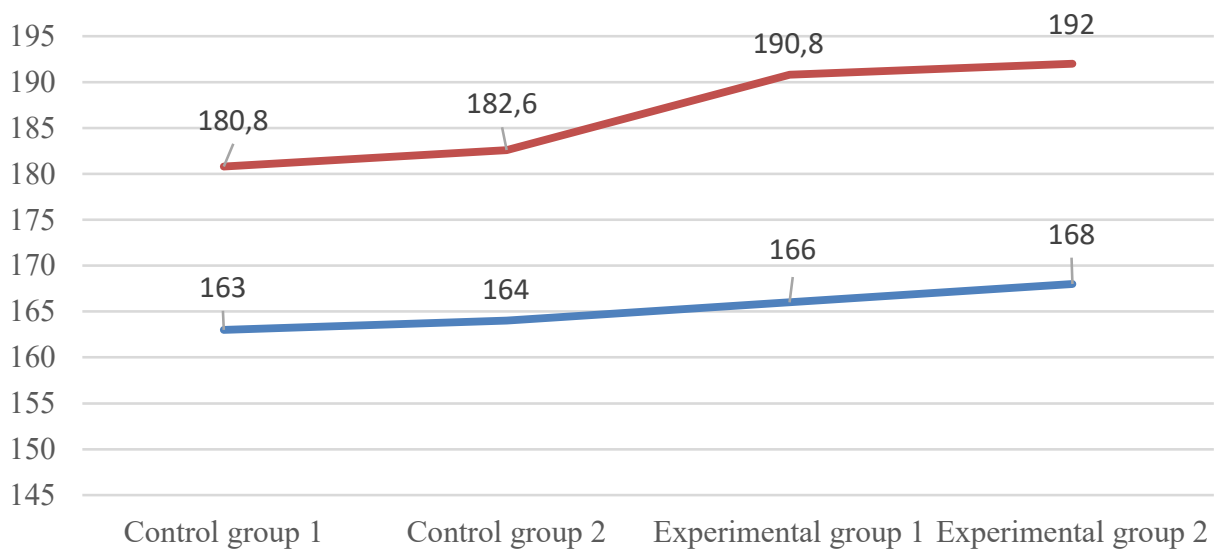

Egg-laying capacity per an initial hen, pcs.
Egg-laying capacity per an average hen, pcs.

Fig. 3. Egg-laying capacity in the experimental groups.

The figure clearly illustrates that the highest egg production indicators for the initial and the average laying hen were in the groups where the bird's feed included crushed sprouted barley. These groups had higher livability for the entire period of the experiment. It was $95.4 \%$ in the first experimental group, $96.4 \%$ in the second experimental group being higher by $0.9 \%$ the indicators in the first control group $(94.5 \%)$ and by $1.9 \%$ in the second control group. In the experimental groups fed the diets with added sprouted barley, the feed conversion was 1.75 and $1.72 \mathrm{~kg} / \mathrm{kg}$, respectively. Therefore, including crushed sprouted barley to the diet of the parent flock poultry has a positive effect on livability, egg production and reduces feed conversion rates.

These findings are consistent with the results of Tatianicheva et al. (2021). The scholars found that sprouted barley added to the basic diet resulted in a $93 \%$ safety indicator or $1.0 \%$ higher than in the control group [10].

\section{Conclusion}

Thus, crushed sprouted barley in the diet of the parent flock hens contributes to better poultry growth and development, increases the weight of incubation eggs by an average of $0.3 \%$, the yield of incubation eggs by $0.5 \%$, hatchability by $0.3 \%$, the number of hatched birds by $0.2 \%$, enlarges the poultry livability, egg production indicators per an initial and an average laying hen, reduces the feed conversion rate.

\section{References}

1. M. Afsharmanesh, A.S. Paghaleh, R. Kheirandish, Comp Clin Pathol 22, 993-998 (2013) https://doi.org/10.1007/s00580-012-1517-3

2. D.A. Blagov, I.V. Mironova, N.A. Fedoseeva, V.V. Glebov, V.I. Kosilov, M.M. Shakhmurzov, IOP Conference Series: Earth and Environmental Science, 613, 012017 (2020) 
3. A.B. Charyev, Poultry farming 1, 47-50. (2016) (In Russ.)

4. A.B. Charyev, R.R. Gadiyev, Izvestiya Orenburg State Agrarian University 1 (51), 119-121 (2015) (In Russ.)

5. L. Morozova, I. Mikolaychik, M. Rebezov, N. Fedoseeva, M. Derkho, R. Fatkullin, A.K. Saken, S. Safronov, V. Kosilov, International Journal of Pharmaceutical Research 12, 2181-2190 (2020)

6. A.G. Narizhny, A.Ch. Jamaldinov, G.S. Pokhodnya, Problems of biology of productive animals 1, 64-70 (2020). (In Russ.)

7. G. Pokhodnya, M. Monedchenko, E. Ulyanich, Animal husbandry of Russia 2, 45-46. (2013) (In Russ.)

8. V.F. Radchikov, V.A. Panova, O.V. Raketskaya, Zootechnical science of Belarus 41, 302-310 (2006) (In Russ.)

9. S. Sugiharto, Livestock Research for Rural Development 33, 3 (2021) http://www.lrrd.org/lrrd33/3/sgh_u3338.html

10. O.E. Tatianicheva, O.A. Popova, A.P. Khokhlova, N.A. Maslova, T.M. Ovchinnikova, Actual issues of agricultural biology 1 (19), 115-124 (2021) (In Russ.)

11. S.V. Vendin, G.S. Pokhodnya, Yu.V. Saenko, Zootechnia 12, 9-13 (2019) (In Russ.) 